\title{
Electroanalytical Characterisation of Dopa Decarboxylase Inhibitors Carbidopa and Benserazide on Multiwalled Carbon Nanotube and Poly(Nile blue A) Modified Glassy Carbon Electrodes
}

\author{
Dilek Kul ${ }^{1,2}$ and Christopher M. A. Brett ${ }^{1}$ \\ ${ }^{1}$ Departamento de Química, Faculdade de Ciências e Tecnologia Universidade de Coimbra, 3004-535 Coimbra, Portugal \\ ${ }^{2}$ Faculty of Pharmacy, Karadeniz Technical University, 61080 Trabzon, Turkey \\ Correspondence should be addressed to Christopher M. A. Brett, cbrett@ci.uc.pt
}

Received 1 March 2011; Accepted 22 March 2011

Academic Editor: Bengi Uslu

Copyright ( 2011 D. Kul and C. M. A. Brett. This is an open access article distributed under the Creative Commons Attribution License, which permits unrestricted use, distribution, and reproduction in any medium, provided the original work is properly cited.

\begin{abstract}
Modified glassy carbon electrodes have been made by deposition of functionalised multiwalled carbon nanotubes (MWCNTs) followed by formation of poly(Nile blue) (PNB) films by electropolymerisation, using potential cycling in $0.1 \mathrm{M}$ phosphate buffer solution (PBS) at $\mathrm{pH}$ 6.0. The electrochemical oxidation of carbidopa (CD) and benserazide (BS) on these MWCNTs/PNBmodified electrodes was investigated using cyclic and differential pulse voltammetry in $0.1 \mathrm{M}$ PBS at different values of pH between 5.0 and 8.0; both CD and BS gave one diffusion-controlled irreversible oxidation peak in cyclic voltammetry. Analytical characterisation of $\mathrm{CD}$ and BS was carried out in 0.1 M PBS, pH 5.0. Peak currents in differential pulse voltammetry were linear over the concentration range of $1 \times 10^{-5}$ to $1 \times 10^{-4} \mathrm{M}$ for $\mathrm{CD}$ and $4 \times 10^{-6}$ to $4 \times 10^{-5} \mathrm{M}$ for BS. The repeatability, precision, and accuracy of the method were also investigated. Higher sensitivities and lower detection limits, of $1.17 \mu \mathrm{M}$ for $\mathrm{CD}$ and $0.50 \mu \mathrm{M}$ for BS, were obtained with this new modified electrode compared with previous studies reported in the literature.
\end{abstract}

\section{Introduction}

Dopa decarboxylase inhibitors are used as part of the treatment for Parkinson's disease. Parkinson's disease (PD) is a degenerative disorder of the central nervous system that affects movement, muscle control, balance, and other functions. The most obvious symptoms are motor related such as tremor, rigidity, slowness of movement, and postural instability $[1,2]$. There is currently no cure for Parkinson's disease. However, medications are used to increase levels of dopamine in the brain of patients with PD and in this way slow down the progression of the disease, since motor symptoms are produced by a lack of dopamine. The main drugs used for Parkinson's disease are levodopa, dopamine agonists, and MAO-B inhibitors [3].

Treatment using levodopa involves it being transformed into dopamine and increasing its level in the central nervous system. However, only $5-10 \%$ of levodopa crosses the bloodbr-ain barrier, and the rest is decarboxylated to dopamine in the metabolism before it reaches the brain, causing various side effects. Carbidopa, (2S)-3-(3,4-dihydroxyphenyl)-2-hydrazino-2-methylpropanoic acid, and benserazide, 2-amino3-hydroxy- $\mathrm{N}^{\prime}$-(2,3,4-trihydroxybenzyl) propanehydrazide, (Scheme 1) are decarboxylase inhibitors of levodopa which are unable to cross the blood-brain barrier themselves and used in combination with levodopa for the treatment of PD. They prevent the carboxylation of levodopa before it reaches the brain and reduce the side effects when high doses of levodopa are used $[4,5]$.

Polymers of dyes such as phenothiazines, phenazines, and phenoxazines have recently been found to be attractive as redox mediators on the surface of solid electrodes [6, 7]. These dyes can be electropolymerised from aqueous solutions to obtain electrochemically active polymers. The 
<smiles>NC(CO)C(=O)NNCc1ccc(O)c(O)c1O</smiles>

(a)<smiles>NC(CO)C(=O)NNCc1ccc(O)c(O)c1O</smiles>

(b)

Scheme 1: Structures of (a) carbidopa and (b) benserazide.

resulting polymers have many advantages such as simple one-step preparation, high stability, and reproducibility. Thus, they can be used as sensors and biosensors for the investigation of the electrochemical characteristics of some carboxylic acids [8] and NADH $[9,10]$.

Nile blue A (NB), one of the phenoxazine dyes, is a wellknown water-soluble electroactive molecule. Electrochemical polymerisation of NB gives a semiconducting poly(Nile blue) (PNB) film. PNB has been used as a mediator for the electrocatalytic oxidation of the nicotinamide coenzymes $\mathrm{NADH}$ and NADPH $[11,12]$ and also used in biofuel cells [13].

Single- (SWCNT) and multiwalled (MWCNT) carbon nanotubes have a great interest due to their properties such as high electrical conductivity, chemical stability, high surface area, and insolubility in all solvents $[14,15]$. The unique and one-dimensional structures of carbon nanotubes lead them to be used in sensors and biosensors [16-19]. CNTs have also been used with conducting polymers as redox mediators to obtain new modified electrodes having good electrical and mechanical properties $[20,21]$.

The goal of this work is to carry out investigation and analytical measurement of carbidopa (CD) and benserazide (BS), which are anti-Parkinsonian agents, with modified glassy carbon (GC) electrodes by using cyclic voltammetry $(\mathrm{CV})$ and differential pulse voltammetry (DPV). Modification was achieved first with functionalised multiwalled carbon nanotubes on the surface of GC electrodes. Nile blue A was then electropolymerised onto MWCNT-modified electrodes by cyclic voltammetry. The analytical measurement of CD and BS was carried out at MWCNT/PNB-modified electrodes in the selected supporting electrolyte. The results obtained for CD and BS were compared.

\section{Experimental}

2.1. Reagents. Nile blue A and N,N-dimethylformamide (DMF) were purchased from Fluka (Switzerland). Carbidopa (CD, $\geq 98 \%, M_{w}: 226.23 \mathrm{~g} / \mathrm{mol}$ ) and benserazide (BS, $\geq 98 \%$, $M_{w}: 293.70 \mathrm{~g} / \mathrm{mol}$ ) were from Sigma (USA), and nitric acid was from Riedel-de Haën (Germany). They were used without further purification.

Multiwalled carbon nanotubes were from NanoLab, USA, with $\sim 95 \%$ purity, $30 \pm 10 \mathrm{~nm}$ diameter and $1-5 \mu \mathrm{m}$ length. For carboxylate functionalisation, $120 \mathrm{mg}$ of MWCNT was stirred in $10 \mathrm{~mL}$ of a $3 \mathrm{M}$ nitric acid for $24 \mathrm{~h}$ at room temperature. The solid product was filtered, then washed with nanopure water until the filtrate became close to neutral $(\mathrm{pH} \approx 7)$, and dried at $80^{\circ} \mathrm{C}$ for $24 \mathrm{~h}$.

Phosphate buffer solutions (PBSs), ionic strength $0.1 \mathrm{M}$, with different $\mathrm{pH}$ values were used both for electropolymerisation of NB and as supporting electrolyte for CD and BS. They were prepared from sodium di-hydrogenphosphate and di-sodium hydrogenphosphate (Riedel-de-Haën, Germany), and the $\mathrm{pH}$ was then adjusted with $5 \mathrm{M} \mathrm{NaOH}$ (Riedel-de Haën, Germany) solution.

Stock solutions of CD and BS $\left(1 \times 10^{-3} \mathrm{M}\right)$ were prepared in nanopure water and stored in the dark and at $+4^{\circ} \mathrm{C}$. Working solutions of $\mathrm{CD}$ and $\mathrm{BS}$ for the voltammetric experiments were prepared by direct dilution of the stock solution with the selected supporting electrolyte just before use.

Millipore Milli-Q nanopure water (resistivity $\geq$ $18 \mathrm{M} \Omega \mathrm{cm}$ ) and analytical reagents were used for preparation of all solutions.

2.2. Instrumentation. A three-electrode electrochemical cell was used for voltammetric experiments. It contained a glassy carbon (GC) working electrode with a diameter of $5.5 \mathrm{~mm}$, a platinum foil as counter electrode, and a saturated calomel electrode (SCE) as reference. Measurements were performed using a computer-controlled $\mu$-Autolab Type II potentiostat/galvanostat with GPES 4.9 software (Metrohm-Autolab, the Netherlands).

The $\mathrm{pH}$ measurements were carried out with a CRISON 2001 micro-pH meter at room temperature.

2.3. Modification of GC Electrodes with MWCNT and PNB. Modification of GC electrodes was achieved with functionalised MWCNT and PNB films. Before modification, the GC electrode was polished with diamond spray (Kemet International Ltd., UK) down to $1 \mu \mathrm{m}$ particle size, then sonicated in Milli-Q nanopure water and rinsed with nanopure water.

The functionalised MWCNTs were dispersed in DMF with loading $0.2 \%(\mathrm{mg} / \mu \mathrm{L})$ and sonicated for $4 \mathrm{~h}$ to obtain a homogeneous mixture. Then, $20 \mu \mathrm{L}$ of the $0.2 \%$ MWCNT/DMF dispersion was dropped directly on the surface of the GC electrode using a micropipette and dried overnight at room temperature.

NB was electropolymerised onto MWCNT coatings (denoted as MWCNT/PNB) by cycling in the potential region from -0.6 to $+1.2 \mathrm{~V}$ versus SCE at a scan rate of $50 \mathrm{mV} \mathrm{s}^{-1}$ in $0.1 \mathrm{M} \mathrm{PBS}$ at $\mathrm{pH} 6.0$ containing $0.5 \mathrm{mM}$ of NB. The optimum number of cycles for electropolymerisation of NB 


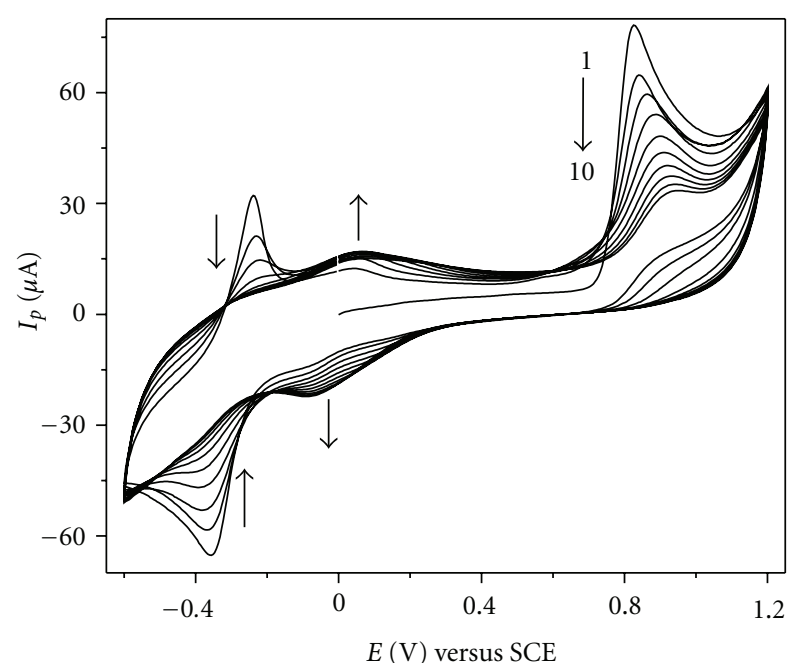

FIGURE 1: Cyclic voltammograms during potential cycling electropolymerisation of $0.5 \mathrm{mM} \mathrm{NB}$ in $0.1 \mathrm{M}$ PBS at $\mathrm{pH}$ 6.0. Scan rate $50 \mathrm{mV} \mathrm{s}^{-1}$.

was found to be 5. After polymerisation, MWCNT/PNBmodified electrodes were dried for $24 \mathrm{~h}$ at room temperature.

2.4. Analytical Procedures. For analytical assays, all solutions were freshly prepared before the experiments and protected from the light. Measurements were carried out using differential pulse voltammetry (DPV) at room temperature $(25 \pm$ $\left.1{ }^{\circ} \mathrm{C}\right)$. The calibration equations for the DPV technique were constructed by plotting the peak current against CD or BS concentration.

Validation of the studied method was carried out with regard to ruggedness, precision, and accuracy by assaying five replicate samples $[22,23]$.

\section{Results and Discussion}

3.1. Electrochemical Polymerisation of Nile Blue. Electropolymerisation of $\mathrm{NB}$ was carried out in $0.1 \mathrm{M}$ PBS at pH 6.0 containing $0.5 \mathrm{mM}$ of NB by potential cycling on the MWCNTmodified electrodes. These polymerisation conditions were chosen according to a detailed study between $\mathrm{pH} 5-8$, which showed that these conditions led to the polymer with the best electrochemical behaviour, with the most well-defined voltammetric peaks and the most stable PNB film [24]. Five cycles were used for the polymerisation of $\mathrm{NB}$, since thicker PNB films, obtained with more than 5 cycles, onto MWCNTs coatings, led to unstable surface modifier films [24].

Cyclic voltammograms during and after NB polymerisation gave two redox couples: oxidation/reduction peaks for NB monomer and PNB polymer at around $-0.4 \mathrm{~V}$ and $0.0 \mathrm{~V}$, respectively. The irreversible oxidation peak at $\sim 0.9 \mathrm{~V}$ is due to formation of the monomer radical (Figure 1). Peak currents for the electropolymerisation of NB onto MWCNT coatings were much higher than those of on the surface of the GC electrode, since modification by MWCNT leads to a larger electroactive surface area $[15,24,25]$.

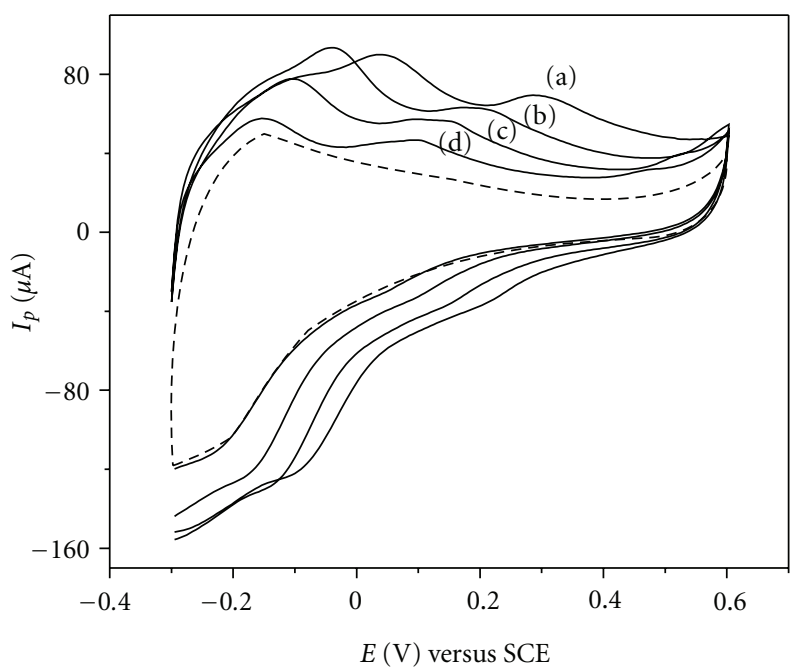

(a)

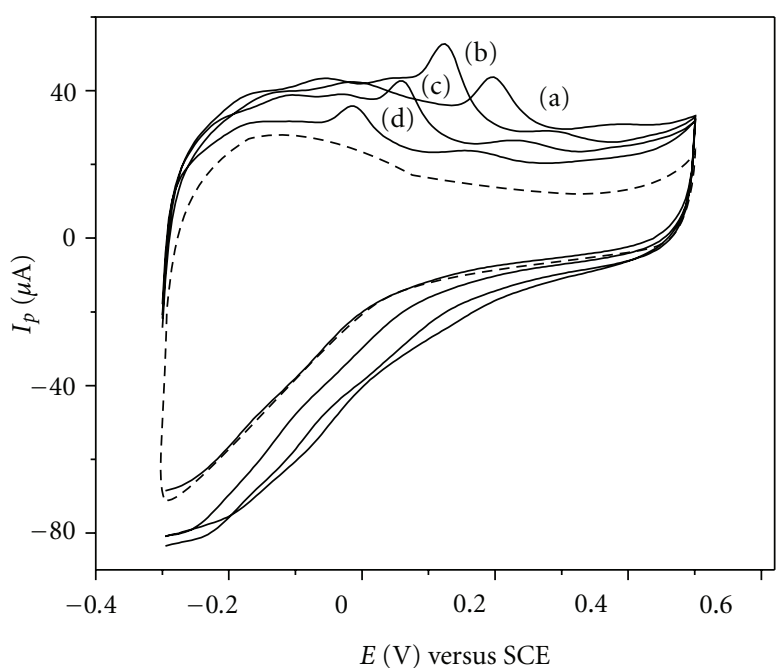

(b)

Figure 2: Cyclic voltammograms of (A) CD and (B) BS in $0.1 \mathrm{M}$ PBS at $\mathrm{pH}$ (a) 5.0, (b) 6.0, (c) 7.0, and (d) 8.0 with MWCNTs/PNBmodified electrode. Dashed lines: $0.1 \mathrm{M}$ PBS at $\mathrm{pH}$ 8.0. CD and BS concentrations: $100 \mu \mathrm{M}$. Scan rate $50 \mathrm{mV} \mathrm{s}^{-1}$.

3.2. Electrochemical Behaviour of CD and BS with Modified Electrodes. The electrochemical oxidation behaviour of $\mathrm{CD}$ and BS was investigated using cyclic voltammetry (CV) with MWCNTs/PNB-modified electrodes in $0.1 \mathrm{M}$ PBS at different $\mathrm{pH}$ values between 5.0 and 8.0. More acidic buffer solutions were not used, since PNB films were unstable in media more acidic than $\mathrm{pH} 5.0$ and media of $\mathrm{pH}>8.0$ cause decomposition of CD and BS.

$\mathrm{CV}$ measurements were made in the region between $-0.3 \mathrm{~V}$ and $0.5 \mathrm{~V}$, scanning in the positive direction at a scan rate of $50 \mathrm{mV} \mathrm{s}^{-1}$ in $0.1 \mathrm{M} \mathrm{PBS}$ at $\mathrm{pH} 5.0,6.0,7.0$, and 8.0 containing $100 \mu \mathrm{M}$ CD or BS; typical cyclic voltammograms are shown in Figure 2. Both CD and BS gave a single broad oxidation peak for all $\mathrm{pH}$ values tested. The oxidation peaks of CD and BS were at 286 and $198 \mathrm{mV}$ versus SCE in $0.1 \mathrm{M}$ 


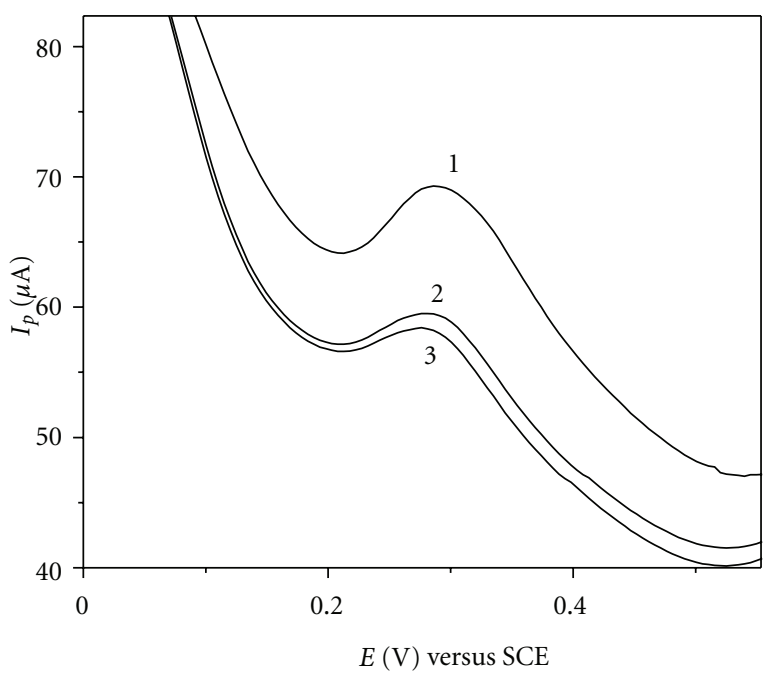

(a)

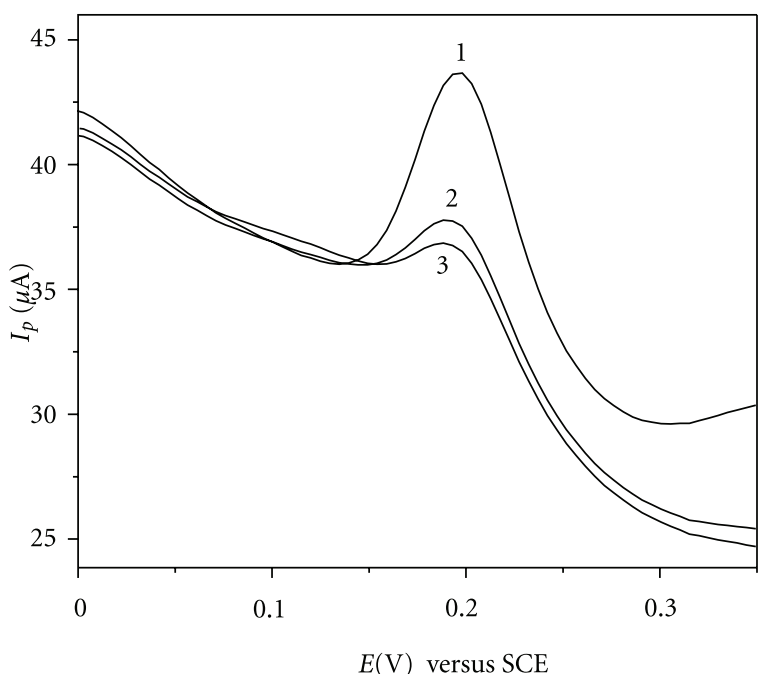

(b)

Figure 3: (1) First cycle, (2) second cycle, and (3) third cycle of the anodic responses of $1 \times 10^{-4} \mathrm{M}$ (a) CD and (b) BS from repetitive voltammograms in $0.1 \mathrm{M}$ PBS at $\mathrm{pH} 5.0$ with MWCNTs/PNBmodified electrode. Scan rate $50 \mathrm{mV} \mathrm{s}^{-1}$.

PBS at $\mathrm{pH}$ 5.0. A very small cathodic response on sweep inversion was observed at around $210 \mathrm{mV}$ for CD but only in $\mathrm{pH} 5.0$ buffer solution. No reduction corresponding to the oxidation of BS was observed on the negative scan. These results demonstrate the irreversible nature of the $\mathrm{CD}$ and $\mathrm{BS}$ oxidation processes. The peaks of CD and BS decreased in the second and later cycles, due to blocking adsorption on the surface of the modified electrodes (Figure 3 ).

The effect of $\mathrm{pH}$ on the peak potential and peak current was investigated at $\mathrm{pH} 5.0,6.0,7.0$, and 8.0 using both $\mathrm{CV}$ and DPV. Since the variations with $\mathrm{pH}$ seen by $\mathrm{CV}$ were similar to those with DPV, only the results obtained with DPV are shown in Figure 4. Both techniques showed that the peak potential of the anodic process moved to less positive potentials with increasing $\mathrm{pH}$ for both $\mathrm{CD}$ and $\mathrm{BS}$.

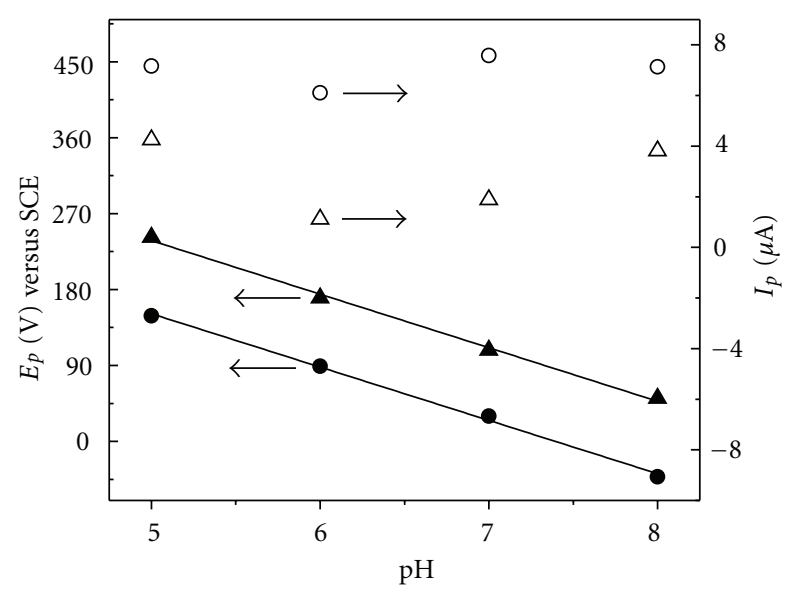

FIGURE 4: Plots of peak potential, $E_{p}$, and peak current, $I_{p}$, versus $\mathrm{pH}$ from $\mathrm{DP}$ voltammograms of $\mathrm{CD}$ and $\mathrm{BS}$ (concentrations $100 \mu \mathrm{M})$ in $0.1 \mathrm{M}$ PBS at MWCNT/PNB-modified electrodes. Triangles indicate CD and circles BS; filled symbols refer to $E_{p}$ and unfilled ones to $I_{p}$.

Anodic peak potentials gave a linear dependence on $\mathrm{pH}$ with a negative slope of $63.5 \mathrm{mV} / \mathrm{pH}$ (correlation coefficient 0.996 ) and $63.2 \mathrm{mV} / \mathrm{pH}$ (correlation coefficient 0.997 ) for $\mathrm{CD}$ and BS, respectively, Figure 4. These slope values are close to the theoretical value of $59 \mathrm{mV} / \mathrm{pH}$, obtained if the numbers of protons and electrons involved in the oxidation process are equal $[6,26]$. The relationship between $\mathrm{pH}$ and peak current of CD and BS was also investigated. The maximum peak current and the better peak shape were obtained in $0.1 \mathrm{M}$ PBS at $\mathrm{pH} 5.0$ for $\mathrm{CD}$ and $\mathrm{pH} 7.0$ for BS. However, BS was not stable at $\mathrm{pH} 7.0$ for sufficient time to complete all of the studies. Thus, phosphate buffer at $\mathrm{pH} 5.0$ was used as supporting electrolyte for the analytical characterisation of both CD and BS.

Scan rate studies were carried out in the range between 5 and $200 \mathrm{mV} \mathrm{s}^{-1}$ by $\mathrm{CV}$ to further assess the electrochemical oxidation of $\mathrm{CD}$ and $\mathrm{BS}$. The oxidation peak potentials shifted to more positive potentials by about $132 \mathrm{mV}$ for $\mathrm{CD}$ and $127 \mathrm{mV}$ for BS when the scan rate was increased. Linear plots were not observed over this range neither from the plots of anodic peak current versus scan rate nor versus the square rate of scan rate, suggesting a more complex behavior. For this reason, plots of logarithm of peak current, $\log \left(I_{p}\right)$ versus logarithm of scan rate, $\log (\nu)$, for $\mathrm{CD}$ and BS were constructed, where a slope of 0.5 means a diffusion-controlled process and of 1.0 signifies an adsorption-controlled or surface-confined electrode process [27]. These plots showed the same tendencies for both CD and BS. At lower scan rates, $\leq 50 \mathrm{mV} \mathrm{s}^{-1}$, the slope of the plot of $\log \left(I_{p}\right)$ versus $\log (v)$ was close to 0.5 , indicative of diffusion control, and then began to increase, indicating that adsorption or thin-layer effects were beginning to have an influence on the observed behaviour. This can be explained talking into account the porous nature of the modifier layer into which the analyte will diffuse: the response is due to oxidation of species diffusing from bulk solution and to 


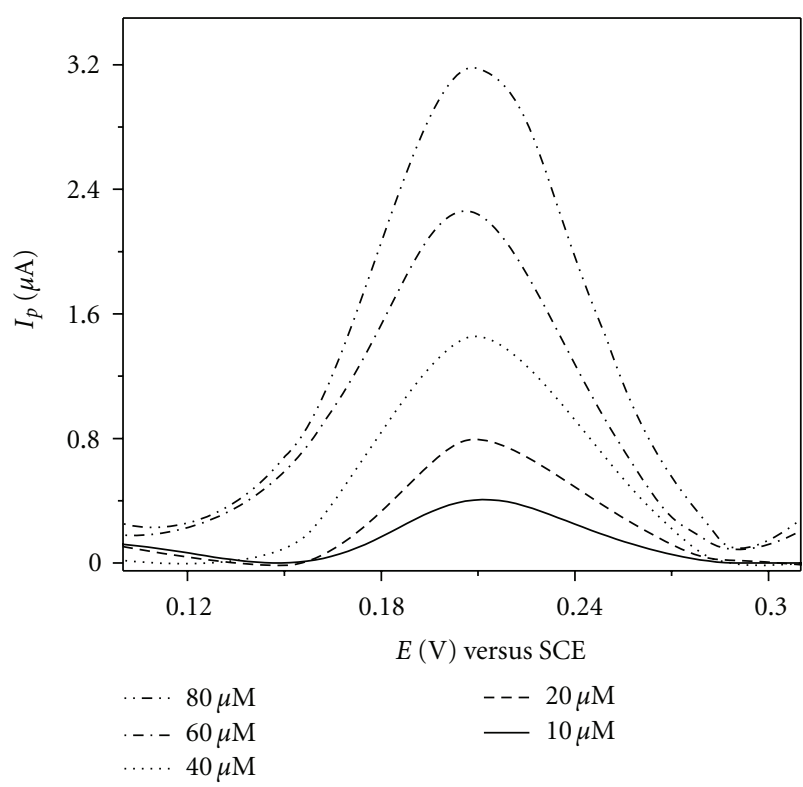

(a)

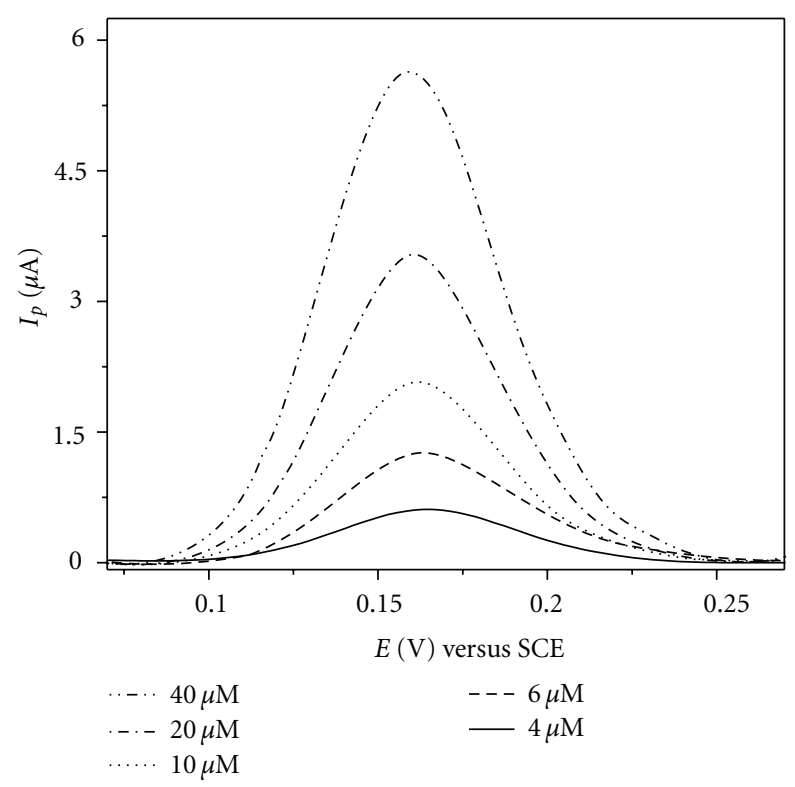

(b)

Figure 5: Baseline-subtracted differential pulse voltammograms of (a) $\mathrm{CD}$ and (b) BS at different concentrations in $0.1 \mathrm{M}$ PBS at $\mathrm{pH}$ 5.0, using a MWCNT/PNB-modified electrode.

these species within the porous structure (similar to surfaceconfined species). As the scan rate increases, the timescale for diffusion decreases and the contribution of the latter becomes proportionally more important.

Tafel plots $(\log I$ versus $E)$ were drawn for the scan rate of $5 \mathrm{mV} \mathrm{s}^{-1}$ beginning at a steady-state potential in $0.1 \mathrm{M}$ $\mathrm{PBS}$ at $\mathrm{pH} 5.0$ for both $\mathrm{CD}$ and BS [27]. The intercepts of the $\log I-f(E)$ plots gave the exchange current density $\left(I_{o}\right)$ values, which were $9.73 \times 10^{-13} \mu \mathrm{A} \mathrm{cm}^{-2}$ and $4.48 \times$ $10^{-13} \mu \mathrm{Acm}^{-2}$ for $\mathrm{CD}$ and $\mathrm{BS}$, respectively. These values
TABLe 1: Data from the calibration plots for the analytical characterisation of $\mathrm{CD}$ and $\mathrm{BS}$ in $0.1 \mathrm{M}$ PBS, $\mathrm{pH} 5.0$ by DPV at the MWCNTs/PNB-modified electrode.

\begin{tabular}{lcc}
\hline & Carbidopa & Benserazide \\
\hline Peak potential $(\mathrm{mV}$ versus SCE) & 210 & 160 \\
Linearity range $(\mu \mathrm{M})$ & $10-100$ & $4-40$ \\
Slope $\left(\mu \mathrm{A} \mu \mathrm{M}^{-1}\right)$ & $0.43 \pm 0.001$ & $0.15 \pm 0.001$ \\
Intercept $(\mu \mathrm{A})$ & $0.49 \pm 0.07$ & $-0.32 \pm 0.02$ \\
Correlation coefficient & 0.997 & 0.999 \\
LOD $(\mu \mathrm{M})$ & 1.17 & 0.50 \\
LOQ $(\mu \mathrm{M})$ & 3.56 & 1.53 \\
Repeatability of peak potential $(\mathrm{RSD} \%)$ & 0.50 & 0.56 \\
Repeatability of peak current $(\mathrm{RSD} \%)$ & 0.96 & 0.44 \\
\hline
\end{tabular}

confirmed the irreversibility of the oxidation reaction for both CD and BS.

3.3. Validation of the Analytical Methods. Differential pulse voltammetry (DPV) is an effective, selective, and sensitive technique which is suitable for the determination of organic drug compounds at low detection limits [28-30]. In this work, DPV was used for the quantitative evaluation of CD and BS, based on the linear correlation between oxidation peak current and concentration in 0.1 M PBS at pH 5.0 for both $\mathrm{CD}$ and $\mathrm{BS}$, since the best response (regarding peak shape, peak current sensitivity, and reproducibility) and the best stability of CD and BS were obtained in this buffer. All solutions used for the analytical experiments were freshly prepared to ensure the stability of the analyte in the solutions.

Calibration plots under the selected conditions and using standard solutions of CD and BS are shown in Figure 5. The linear range was $1 \times 10^{-5}$ to $1 \times 10^{-4} \mathrm{M}$ for $\mathrm{CD}$ and $4 \times 10^{-6}$ to $4 \times 10^{-5} \mathrm{M}$ for BS; higher concentrations of $\mathrm{CD}$ and $\mathrm{BS}$ led to the loss of linearity and saturation effects that can be attributed to the effect of adsorption of species on the surface of MWCNT/PNB-modified electrode. The characteristics of the calibration lines and their related validation parameters are summarized in Table 1. Low values of standard error of the slopes and intercepts and correlation coefficients greater than 0.996 for both $\mathrm{CD}$ and $\mathrm{BS}$ confirmed the precision of the proposed method at MWCNT/PNB-modified electrodes.

The method was validated according to standard procedures $[22,31]$. Accuracy, precision, and ruggedness were assessed by performing replicate analysis of the standard solutions in the supporting electrolyte. Limits of detection (LOD), limits of quantification (LOQ), repeatability (within day), precision, and selectivity were evaluated for both $\mathrm{CD}$ and BS $[23,29]$. The LOD and LOQ were calculated from the peak currents using LOD $=3 \mathrm{~s} / \mathrm{m}$ and LOQ $=10 \mathrm{~s} / \mathrm{m}$, where $s$ is the standard deviation of the peak currents (three runs) and $\mathrm{m}$ is the slope of the related calibration equation [32]. Also, these results indicated the reliability of the proposed voltammetric technique for the trace assay of $\mathrm{CD}$ and $\mathrm{BS}$.

The precision of the method was calculated from five replicate experiments in different solutions having the same 
concentration of $\mathrm{CD}$ or BS within the same day (repeatability) using DPV at the MWCNT/PNB-modified electrode. The concentrations of $\mathrm{CD}$ and $\mathrm{BS}$ for these studies were $8 \times 10^{-5} \mathrm{M}$ and $6 \times 10^{-5} \mathrm{M}$, respectively. The precision and accuracy were determined as R.S.D.\% (Table 1). These results demonstrate a good precision, accuracy, and sensitivity.

Electroanalytical studies of carbidopa and benserazide can also be found in the literature, which use differential pulse voltammetry. In [33], linear ranges between $31 \mu \mathrm{M}$ and $470 \mu \mathrm{M}$ with current sensitivity of $0.028 \mu \mathrm{A} \mu \mathrm{M}^{-1}$ and an LOD value of $2.16 \mu \mathrm{M}$ were determined for $\mathrm{CD}$ and linear range $31 \mu \mathrm{M}$ to $620 \mu \mathrm{M}$ with current sensitivity $0.054 \mu \mathrm{A} \mu \mathrm{M}^{-1}$ and LOD of $2.77 \mu \mathrm{M}$ for BS at GC electrodes. In another study [34], quantitative analysis of CD was carried out by DPV in the linear range from $5 \mu \mathrm{M}$ to $600 \mu \mathrm{M}$ with $3.6 \mu \mathrm{M}$ of LOD and a current sensitivity of $0.041 \mu \mathrm{A} \mu \mathrm{M}^{-1}$ using ferrocene-modified carbon nanotube paste electrodes. In this work using MWCNTs/PNB-modified electrodes, as shown in Table 1, the sensitivity is significantly higher and the LOD lower than in the articles mentioned above.

\section{Conclusions}

Glassy carbon electrodes have been modified by coating with MWCNT and then poly(Nile blue), by drop coating with $20 \mu \mathrm{L}$ of $0.2 \%$ MWCNT/DMF and then polymerising NB electrochemically in 0.1 M PBS at pH 6.0.

The MWCNT/PNB-modified electrode was used to investigate the electrochemical behaviour of the anti-Parkinsonian agents carbidopa and benserazide, Cyclic voltammetric measurements showed an irreversible behaviour in $0.1 \mathrm{M}$ $\mathrm{PBS}$ at all $\mathrm{pH}$ values for both $\mathrm{CD}$ and BS. From the relationship of $\mathrm{pH}$ and peak currents and shapes, $0.1 \mathrm{M}$ PBS at $\mathrm{pH}$ 5.0 was selected as supporting electrolyte for further studies. Scan rate studies showed that the process of MWCNT/PNBmodified electrodes was diffusion controlled with some evidence of thin-layer behaviour at high scan rate.

Analytical characterisation of CD and BS was achieved using DPV as a rapid, selective, sensitive, cheap, and simple technique. Linear calibration curves were obtained for both CD and BS. It was shown that the DPV method used gave good precision, accuracy, and sensitivity for CD and BS.

\section{Acknowledgments}

Financial support from Fundação para a Ciência e a Tecnologia (FCT), PTDC/QUI/65255/2006 and PTDC/QUI/65732/ 2006, POCI 2010 (cofinanced by the European Community Fund FEDER) and CEMUC (Research Unit 285), Portugal, is gratefully acknowledged. D. Kul thanks T.C., the Council of Higher Education (YÖK, Turkey) for a Postdoctoral research fellowship and Karadeniz Technical University (Turkey).

\section{References}

[1] J. Jankovic, "Parkinson's disease: clinical features and diagnosis," Journal of Neurology, Neurosurgery and Psychiatry, vol. 79, no. 4, pp. 368-376, 2008.
[2] C. A. Davie, "A review of Parkinson's disease," British Medical Bulletin, vol. 86, no. 1, pp. 19-127, 2008.

[3] S. Fahn, "The history of dopamine and levodopa in the treatment of Parkinson's disease," Movement Disorders, vol. 23, no. 3, pp. 497-508, 2008.

[4] The National Collaborating Centre for Chronic Conditions, "Symptomatic pharmacological therapy in Parkinson's disease," in Parkinson's Disease, pp. 59-100, Royal College of Physicians, London, UK, 2006.

[5] J. Goole and K. Amighi, "Levodopa delivery systems for the treatment of Parkinson's disease: an overview," International Journal of Pharmaceutics, vol. 380, no. 1-2, pp. 1-15, 2009.

[6] M. E. Ghica and C. M. A. Brett, "Poly(brilliant cresyl blue) modified glassy carbon electrodes: electrosynthesis, characterisation and application in biosensors," Journal of Electroanalytical Chemistry, vol. 629, no. 1-2, pp. 35-42, 2009.

[7] R. Pauliukaite, M. E. Ghica, M. M. Barsan, and C. M. A. Brett, "Phenazines and polyphenazines in electrochemical sensors and biosensors," Analytical Letters, vol. 43, no. 10-11, pp. 1588-1608, 2010.

[8] R. Pauliukaite, M. E. Ghica, M. Barsan, and C. M. A. Brett, "Characterisation of poly(neutral red) modified carbon film electrodes; Application as a redox mediator for biosensors," Journal of Solid State Electrochemistry, vol. 11, no. 7, pp. 899908, 2007.

[9] D. Dicu, L. Muresan, I. C. Popescu, C. Cristea, L. A. Silberg, and P. Brouant, "Modified electrodes with new phenothiazine derivatives for electrocatalytic oxidation of $\mathrm{NADH}$," Electrochimica Acta, vol. 45, no. 24, pp. 3951-3957, 2000.

[10] M. E. Ghica, R. Pauliukaite, N. Marchand, E. Devic, and C. M. A. Brett, "An improved biosensor for acetaldehyde determination using a bienzymatic strategy at poly(neutral red) modified carbon film electrodes," Analytica Chimica Acta, vol. 591, no. 1, pp. 80-86, 2007.

[11] A. S. Santos, L. Gorton, and L. T. Kubota, "Nile blue adsorbed onto silica gel modified with niobium oxide for electrocatalytic oxidation of NADH," Electrochimica Acta, vol. 47, no. 20, pp. 3351-3360, 2002.

[12] P. Du, P. Wu, and C. Cai, "A glucose biosensor based on electrocatalytic oxidation of NADPH at single-walled carbon nanotubes functionalized with poly(Nile blue A)," Journal of Electroanalytical Chemistry, vol. 624, no. 1-2, pp. 21-26, 2008.

[13] Y. M. Yan, O. Yehezkeli, and I. Willner, "Integrated, electrically contacted NAD $(\mathrm{P})$-dependent enzyme-carbon nanotube electrodes for biosensors and biofuel cell applications," Chemistry: A European Journal, vol. 13, no. 36, pp. 10168-10175, 2007.

[14] G. A. Rivas, M. D. Rubianes, M. C. Rodríguez et al., "Carbon nanotubes for electrochemical biosensing," Talanta, vol. 74, no. 3, pp. 291-307, 2007.

[15] Q. Gao, M. Sun, P. Peng, H. Qi, and C. Zhang, "Electrooxidative polymerization of phenothiazine dyes into a multilayer-containing carbon nanotube on a glassy carbon electrode for the sensitive and low-potential detection of NADH," Microchimica Acta, vol. 168, no. 3, pp. 299-307, 2010.

[16] M. E. Ghica, R. Pauliukaite, O. Fatibello-Filho, and C. M. A. Brett, "Application of functionalised carbon nanotubes immobilised into chitosan films in amperometric enzyme biosensors," Sensors and Actuators B, vol. 142, no. 1, pp. 308$315,2009$.

[17] A. I. Gopalan, K. P. Lee, and D. Ragupathy, "Development of a stable cholesterol biosensor based on multi-walled carbon nanotubes-gold nanoparticles composite covered with a layer of chitosan-room-temperature ionic liquid network," 
Biosensors and Bioelectronics, vol. 24, no. 7, pp. 2211-2217, 2009.

[18] P. Yanez-Sedeno, J. Riu, J. M. Pingarron, and F. X. Rius, "Electrochemical sensing based on carbon nanotubes," Trends in Analytical Chemistry, vol. 29, pp. 939-953, 2010.

[19] Y. Zhang, J. Wang, and M. Xu, "A sensitive DNA biosensor fabricated with gold nanoparticles/poly ( $\mathrm{p}$-aminobenzoic acid)/carbon nanotubes modified electrode," Colloids and Surfaces B, vol. 75, no. 1, pp. 179-185, 2010.

[20] P. Du, B. O. Zhou, and C. Cai, "Development of an amperometric biosensor for glucose based on electrocatalytic reduction of hydrogen peroxide at the single-walled carbon nanotube/Nile blue A nanocomposite modified electrode," Journal of Electroanalytical Chemistry, vol. 614, no. 1-2, pp. 149-156, 2008.

[21] G.M. Nascimento, R. C. Oliveira, N. A. Pradie et al., "Singlewall carbon nanotubes modified with organic dyes: synthesis, characterization and potential cytotoxic effects," Journal of Photochemistry and Photobiology A, vol. 211, no. 2-3, pp. 99$107,2010$.

[22] J. Ermer and J. H. Miller, Eds., Method Validation in Pharmaceutical Analysis, Wiley-VCH, Weinheim, Germany, 2005.

[23] P. Bievre and H. Günzler, Validation in Chemical Measurements, Springer, New York, NY, USA, 2005.

[24] D. Kul, R. Pauliukaite, and C. M. A. Brett, "Electrosynthesis and characterisation of poly(Nile blue) films," submitted.

[25] X. Chen, F. Wang, and Z. Chen, "An electropolymerized Nile blue sensing film-based nitrite sensor and application in food analysis," Analytica Chimica Acta, vol. 623, no. 2, pp. 213-220, 2008.

[26] M. S. Maia Quintino, M. Yamashita, and L. Angnes, "Voltammetric studies and determination of levodopa and carbidopa in pharmaceutical products," Electroanalysis, vol. 18, no. 7, pp. 655-661, 2006.

[27] E. Laviron, L. Roullier, and C. Degrand, "A multilayer model for the study of space distributed redox modified electrodes. Part II. Theory and application of linear potential sweep voltammetry for a simple reaction," Journal of Electroanalytical Chemistry, vol. 112, no. 1, pp. 11-23, 1980.

[28] B. Dogan, A. Golcu, M. Dolaz, and S. A. Ozkan, "Electrochemical behaviour of the bactericidal cefoperazone and its selective voltammetric determination in pharmaceutical dosage forms and human serum," Current Pharmaceutical Analysis, vol. 5, no. 2, pp. 179-189, 2009.

[29] D. Kul, M. Gumustas, B. Uslu, and S. A. Ozkan, "Electroanalytical characteristics of antipsychotic drug ziprasidone and its determination in pharmaceuticals and serum samples on solid electrodes," Talanta, vol. 82, no. 1, pp. 286-295, 2010.

[30] D. Kul, B. Uslu, and S. A. Ozkan, "Electrochemical determination of anti-hyperlipidemic drug ezetimibe based on its oxidation on solid electrodes," Analytical Letters. In press.

[31] B. Uslu, B. D. Topal, and S. A. Ozkan, "Electroanalytical investigation and determination of pefloxacin in pharmaceuticals and serum at boron-doped diamond and glassy carbon electrodes," Talanta, vol. 74, no. 5, pp. 1191-1200, 2008.

[32] I. R. Berry and D. Harpaz, Validation of Active Pharmaceutical Ingredients, CRC Press, Washington, DC, USA, 2nd edition, 2001.

[33] C. Zapata-Urzua, M. Perez-Ortiz, M. Bravo, A. C. Olivieri, and A. Lueje, "Simultaneous voltammetric determination of levodopa, carbidopa and benserazide in pharmaceuticals using multivariate calibration," Talanta, vol. 82, no. 3, pp. 962-968, 2010.
[34] H. Yaghoubian, H. Karimi-Maleh, M. A. Khalilzadeh, and F. Karimi, "Electrochemical detection of carbidopa using a ferrocene-modified carbon nanotube paste electrode," Journal of the Serbian Chemical Society, vol. 74, no. 12, pp. 1443-1453, 2009. 


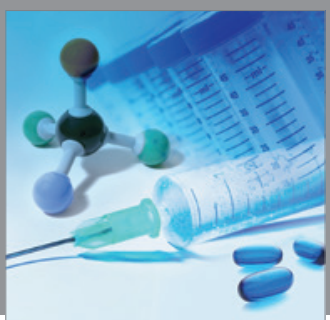

International Journal of

Medicinal Chemistry

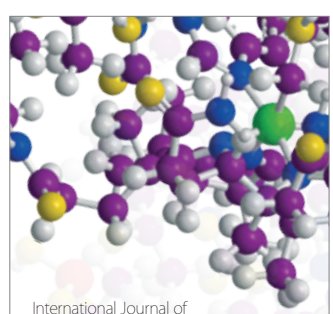

Carbohydrate Chemistry

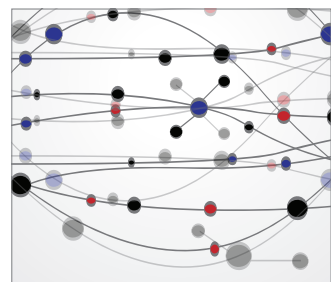

The Scientific World Journal
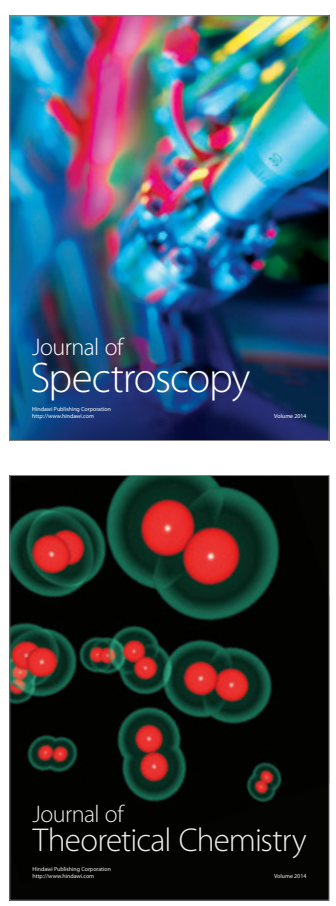
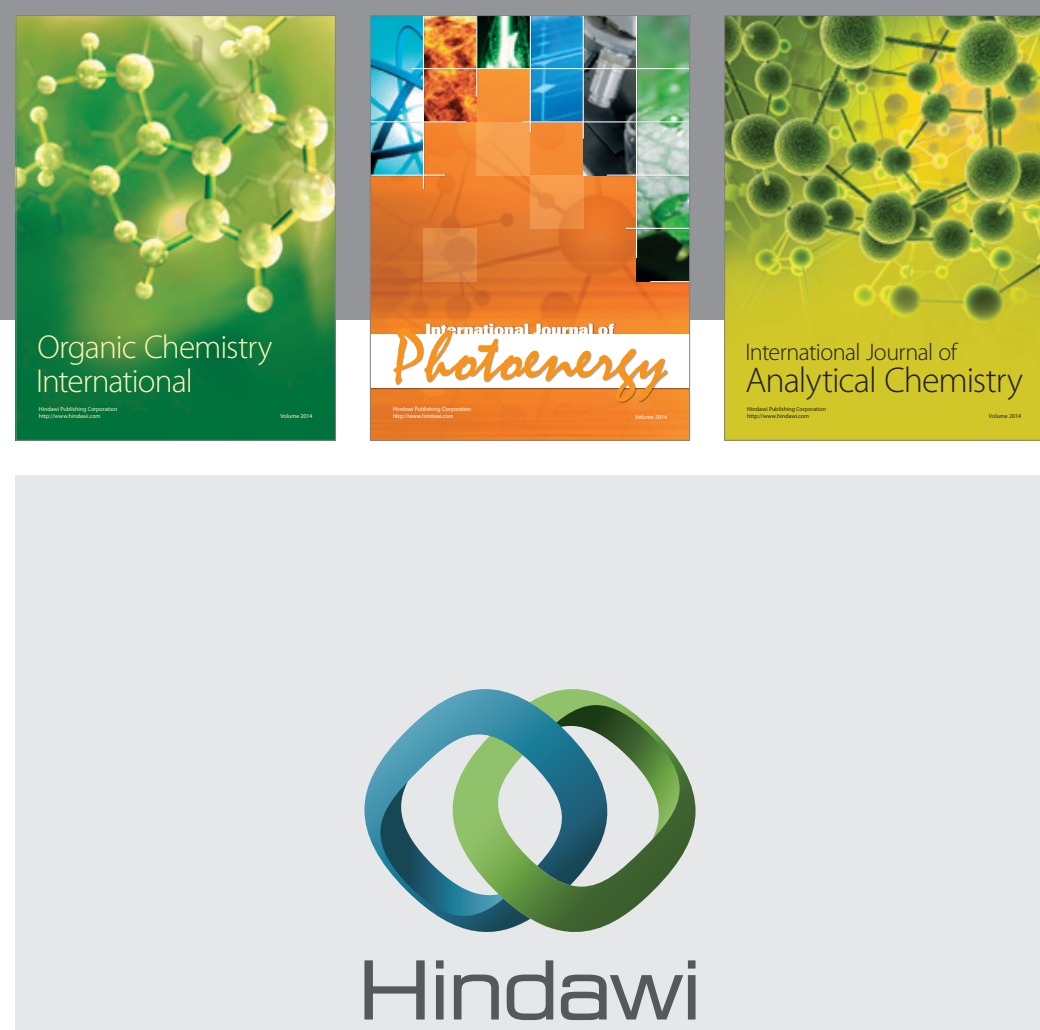

Submit your manuscripts at

http://www.hindawi.com
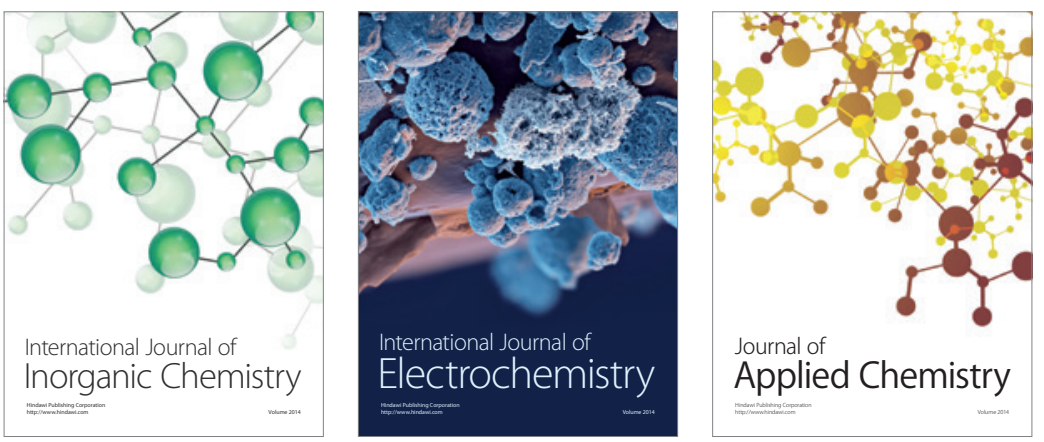

Journal of

Applied Chemistry
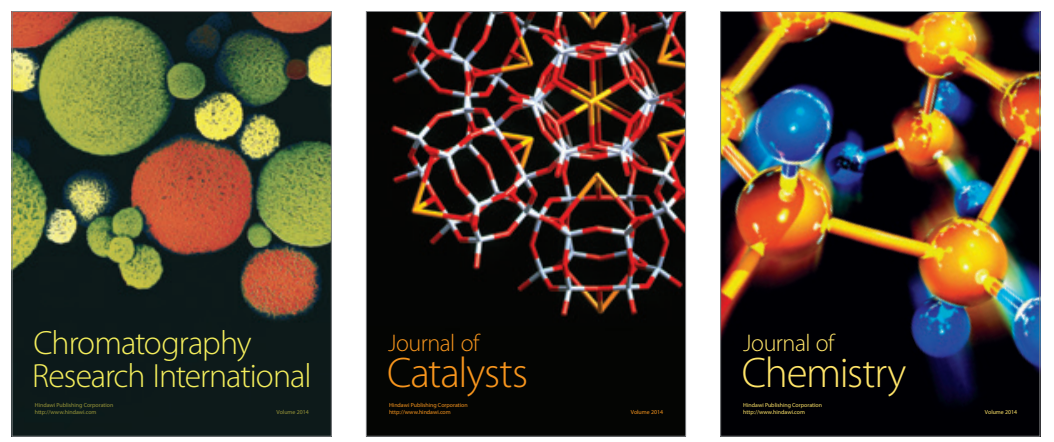
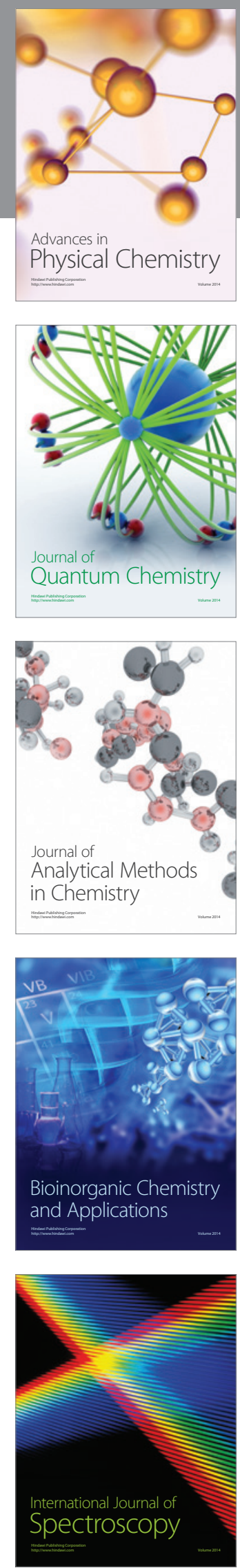